\title{
AGSHARE OPEN KNOWLEDGE: IMPROVING RURAL COMMUNITIES THROUGH UNIVERSITY STUDENT ACTION RESEARCH
}

\author{
Christine Geith, Ph.D. \\ MSUglobal Knowledge and Learning Innovations \\ Michigan State University
}

Karen Vignare, Ph.D.

University of Maryland University College

\section{KEYWORDS}

Open educational resources, Africa, agriculture, curriculum development, higher education, OpenCourseWare, OER, open content, food, agriculture, development, open knowledge, research, development, international, AgShare, participatory action research, case study

\section{INTRODUCTION}

The aim of AgShare is to create a scalable and sustainable collaboration of existing organizations for African publishing, localizing, and sharing of science-based teaching and learning materials that fill critical resource gaps in the African master of science (MSc) agriculture curricula. Shared innovative practices are emerging through the AgShare projects, not only for creating and sharing open educational resources (OERs), but also for collaborating with stakeholders and students to bridge the gap between theory and local practice in African university agriculture curricula [1]. AgShare also involves advocating for and finding open resources in agriculture that can be shared and customized by users. AgShare includes training for faculty but also incorporates the development of open content created by students, farmers, and community partners. Technical work supports improvements in distribution of OERs so that open resources are more easily searched and found, making re-use of them more common. AgShare is having a promising impact on curricula innovation, faculty practice, student research, and agricultural organizations [2].

In 2009, AgShare was co-created by Michigan State University, OER Africa (an initiative of the South African Institute for Distance Education), and faculty at four African universities: Makerere University in Uganda, United States International University in Kenya, Moi University in Kenya, and Haramaya University in Ethiopia. Having successfully completed a two-year planning and pilot project, AgShare is currently in Phase II with the support of a second round of funding from the Bill \& Melinda Gates Foundation and partnership with RUFORUM (Regional Universities Forum for Capacity Building in Agriculture).

\section{BACKGROUND}

Agricultural education in African universities is severely hampered by out-of-date graduate teaching materials, coupled with inadequate funding to purchase new textbooks and teaching aids [3]. If planned and implemented properly, OERs can help overcome these limitations because by their very nature, OERs are produced to be shared, modified, and made freely available through learning networks. When Internet access is routinely available throughout Africa, OERs will be able to reach their full potential, and 
demand for easily accessible materials will grow dramatically. In the meantime, OERs can be distributed off-line in print and DVD formats.

African agricultural education is also severely limited by the gaps between classroom teaching and the research that positively affects farming practice and rural well-being. At present, stakeholders, particularly farmers as the end-users of the technology, generally contribute little to identifying research or curriculum priorities. Moreover, faculty originate from urban areas and have limited firsthand agricultural experience. Additionally, linkages with external stakeholders are not well established or supported to convey important current information on the status of regional agricultural challenges. The result is that many students and faculty are disconnected from the context and issues of smallholder farmers [4]. The effectiveness of agricultural technology generation and dissemination systems requires improved responsiveness to farmer needs.

\section{METHODOLOGY}

\section{A. Exploring the Landscape}

Three activities helped inform the definition of the problem space, which would ultimately be addressed by the planning and pilot phase of the AgShare project. The first activity was a report commissioned by the Bill \& Melinda Gates Foundation to Michigan State University in 2008, which summarized the lay of the land for OER in agriculture and analyzed potential models for using OER for masters curricula in agriculture in Africa [5]. The report, an inventory of known agriculture OERs, indicated that there is not yet a critical mass of OERs in the field, suggesting that opportunities exist to shape new resources and to include communities in collaborative creation of local resources for effective graduate student training.

Following the report, a meeting was held in the United States in February 2009 that explored the potential for OERs in more detail and laid the groundwork for collaboration. Participants included RUFORUM; U.S. land-grant universities, including Michigan State University and Washington State University; Creative Commons; WikiEducator; Connexions; OER Africa; and the William and Flora Hewlett Foundation. These meeting participants confirmed that OER products and processes are an emerging way to recapitalize higher education in the agriculture sector in Africa in several ways: OERs bring openness and transparency to the process of creating and sharing knowledge locally and globally; OERs bring flexibility and adaptability to knowledge products; and publishing knowledge using OER methods enables scalability as well as localization of teaching and learning resources. A second meeting was held in Nairobi, Kenya, in March 2009. Participants included RUFORUM, Michigan State University, OER Africa, FLOSS4Edu, and the Women of Uganda Network. This meeting explored potential African collaboration and discussed potential solutions for farmer impact using OERs.

During the array of meetings leading up to the AgShare planning and pilot project, participants concluded that OERs could be a promising methodology to bridge gaps in the curricula. These participants hypothesized that by observing farming practices and listening carefully to local farmers during field research, students and faculty could incorporate this information into course materials. It is a potential strategy for the creation and co-creation of knowledge; a method by which African university faculty, students, and scientists can share their knowledge not only in the classroom, but also across the nation, the continent, and the globe. These OER materials could be openly shared and re-used as case studies and best practices in classroom teaching. Equally significant-not only could the OER content be useful, but the process of co-creation itself is also valuable in building the capacity of participating faculty and students to be responsive to farmers' needs.

\section{B. Developing the AgShare Planning and Pilot Phase}

The results of the exploration stage informed the vision and rationale for designing the planning and pilot project for AgShare. Summarized in table 1, the rationale resulting from the exploration stage includes issues and assumptions on which the AgShare design is based, as well as indicators that formed a partial foundation of the evaluation metrics of the pilot projects. 


\begin{tabular}{|l|l|}
\hline Rationale & Indicators \\
Teaching materials in African & $\begin{array}{l}\text { Breadth and depth of current teaching materials are not aligned } \\
\text { with defined learning outcomes } \\
\text { Lack of relevant, science-based examples to illustrate theory }\end{array}$ \\
\hline $\begin{array}{l}\text { There is a disconnect between } \\
\text { agriculture graduate studies and the } \\
\text { needs of small farms. }\end{array}$ & $\begin{array}{l}\text { Topics in agriculture curricula not aligned with needs of small } \\
\text { farms } \\
\text { Low level of student and faculty interaction with farmers }\end{array}$ \\
\hline $\begin{array}{l}\text { Graduate study curricula are not aligned } \\
\text { with the public and private employment } \\
\text { sectors. }\end{array}$ & $\begin{array}{l}\text { Topics in agriculture curricula not aligned with needs of } \\
\text { employment sectors } \\
\text { Fewer degree options available in high-demand careers } \\
\text { Low level of student and faculty interaction with employment } \\
\text { sectors }\end{array}$ \\
\hline $\begin{array}{l}\text { Current curricula are static; } \\
\text { incorporating OER modules makes } \\
\text { ongoing change easier. }\end{array}$ & $\begin{array}{l}\text { OER materials currently contribute less to enriched and } \\
\text { modified curricula }\end{array}$ \\
\hline Student learning is passive. & $\begin{array}{l}\text { Low amount of OERs that students author and co-author } \\
\text { Student feedback not necessarily incorporated into curricula } \\
\text { development process } \\
\text { Pedagogy is based primarily on lecture }\end{array}$ \\
\hline $\begin{array}{l}\text { Recognition for the OER sector's } \\
\text { potential growth in Africa is growing. }\end{array}$ & $\begin{array}{l}\text { Low number of OERs available } \\
\text { Low visibility of African OERs }\end{array}$ \\
\hline
\end{tabular}

Table 1. AgShare Planning \& Pilot Rationale

AgShare's long-term vision of success is to have a scalable, sustainable, and open system for African publishing, localizing, and sharing of teaching and learning materials. These materials are intended to fill critical resource gaps in African MSc agriculture curricula and can be modified for other downstream uses. The long-term goal is the sustainable use of AgShare methods, driven particularly by ongoing student engagement in community research, content development, and knowledge-sharing activities in postgraduate programs at African universities actively supporting agricultural communities to effect positive change across key identified agricultural value chains. The primary planned outcome of AgShare is the abundant creation and use of new and revised teaching and learning materials, particularly in areas where critical knowledge is in demand in African MSc agriculture curricula. Secondary planned outcomes are professional development for university faculty and staff, including the creation of open training materials; downstream modification of new and relevant content for extension and non-governmental organization staff; increased active student learning through the collaborative creation and use of OERs; and the establishment of feedback loops involving educational, research, extension, and farming communities for continual improvement and localization of materials.

Proof-of-concept projects were designed to create a strong evidence base for the value of harnessing OERs to support the development of agriculture in Africa. The AgShare planning and pilot project included objectives to demonstrate the following:

1. Course materials can be created relatively rapidly and cost effectively in areas of need by both harnessing the research work of students and by adapting existing openly available educational resources rather than developing them from scratch.

2. Deployment of such course materials into higher education programs, if designed according to sound educational principles, can lead to direct and immediate improvements in the quality of the learning experience and thus create enhanced conditions for improving learning outcomes for learners participating in those programs.

3. Where course materials are developed as OERs against clearly defined educational needs, there are immediate and practical opportunities to facilitate their re-use by other university agriculture faculty. 
4. Actively engaging students in the production of educational materials will enhance their own learning experiences.

5. Structured relationships between academics, students, content suppliers, and community-wide partners, such as farmers, farmers' associations, and agribusinesses, can be built through the facilitation and sharing of OERs. This process can have positive impact for all parties.

6. Once OERs have been created for specific educational purposes (e.g., a master's degree program) through structured relationships, it becomes easier and less costly to re-package these materials for different target audiences (for example, farmers or agribusinesses) than if one seeks to produce materials separately for each of these target audiences.

\section{Selecting Pilot Partners}

Project leaders identified universities as anchor partners, with the understanding that to align with MSc agriculture curricula gaps, the starting point is faculty and their needs for teaching materials. Our first strategy for engaging potential university partners was via circulation of a needs assessment questionnaire examining the unmet needs of different postgraduate programs in agriculture. The questionnaire was circulated to selected schools, based on recommendations from two well-established African university consortia in agriculture universities specifically focused on the construction of regional master's degree programs: RUFORUM and the Collaborative Masters Program in Agricultural and Applied Economics (CMAAE). We limited the geographic scope of initial partners to East Africa, where CMAAE, RUFORUM, and OER Africa are headquartered, in order to contain travel costs.

Through discussion with RUFORUM, it was decided to focus on the Agriculture Information Communication Management Program, as there are clear and immediate needs for development of materials, thus providing a timely opportunity to test the creation and use of a full course using an OER that can be easily adapted and replicated across the RUFORUM network of universities. Haramaya University was selected by RUFORUM to participate in the pilot because it is actively involved in the development of the Agriculture Information Communication Management Program. Through circulation of the CMAAE questionnaire, Moi University in Kenya and Haramaya University in Ethiopia were selected because they demonstrated the greatest willingness to participate. Makerere University was selected because it is one of the oldest institutions in Africa and is internationally known in research and graduate training programs in agriculture. Additionally, it has a strong infrastructure and reputation for managing and participating in international projects relating to research and graduate training. United States International University, Kenya, was selected, as it is a leading business school seeking to develop a pedagogical model and a framework that utilizes a practical case method and active learning processes to assist farmers to transform their traditional practice of farming as a livelihood to farming as a business enterprise.

\section{Capacity Building}

A kick-off planning meeting was held to begin the AgShare pilot and planning project. During the event, the leadership team at each pilot developed their plans and deliverables with the support of Michigan State University faculty and OER Africa. Following the planning, OER Africa worked closely with each pilot partner, providing consultant and project management support, as well as providing documentation and training through workshops at each of the pilot sites. Examples of capacity-building topics in the AgShare support for each pilot include the following:

- Introduction to the concept and principles of OER

- Identification and collection of suitable existing OERs to support materials development

- Instructional design training

- Peer-review processes

- Identification of suitable multimedia components

- Uploading of materials on learner management systems

- Introduction to videography, imagery, and recording 
- Materials quality improvement processes

- Packaging of materials in to various formats; e.g., paper based and electronic

\section{E. Evaluating Pilot Outcomes}

Each pilot project used different strategies to achieve the goals for the AgShare planning and pilot phase. The impact on teaching and learning was assessed by two external evaluators in relation to student researchers who conducted the research on farms: students who experienced the multimedia modules that were produced and academic staff who supervised the research and underpinned the OERs they developed and taught to their students. The first evaluator provided an interim report on whether the understanding of OER and the AgShare methods were growing as result of the pilots [6]. The second evaluator used education theories on the contexts of learning, the teacher/student relationship, and the structure of curriculum to analyze project documents and interview data [7]. This evaluator also examined the outputs of the planning and pilot phase against planned objectives, including the use of created OERs adopted by faculty beyond those in the pilot.

\section{FINDINGS}

The AgShare method, as implemented in the planning and pilot phase, is founded on field-based research carried out by faculty and students. That research served three purposes in most cases: (1) underpinning research-based teaching through case studies, (2) feeding back information to the farming community to improve practices there, and (3) supporting master's thesis research.

Partner universities constructed their individual pilots in line with regional needs, as well as institutional ethos, priorities, strengths, and constraints. The faculty participated in a series of workshops provided by OER Africa. The faculty who participated found they could apply AgShare methods and OERs to various community research needs [6]. As a result, the faculty electing to begin with OER production for their own master's students developed commodity-focused case studies in relation to coffee, maize, the dairy value chain, and agricultural extension. In these cases, the downstreaming of materials to farmers was via a follow-up activity. In some instances, these materials have been used as an integrated part of community development initiatives run by the universities.

One example of this approach was the Makerere University graduate student action research model, which used a dairy industry value chain approach and involved an interdisciplinary team of scientists from the Colleges of Veterinary Medicine and Agriculture. This approach successfully demonstrated that outcomes of graduate students' action research can be used to effect positive change along the whole dairy value chain. In addition, the information generated from the graduate students' action research has been used to create teaching modules with relevant field case examples to be used at universities. Thus, the students have served as agents of positive change.

\section{A. OER Products}

The AgShare pilot projects produced a wide range of publicly available and easily localized OERs in several different media. The materials are disseminated through the OER Africa website (http://www.oerafrica.org/agshare/AgShareResources/tabid/1405/Default.aspx). These materials are integrated into program delivery at the four pilot universities across Ethiopia, Uganda, and Kenya. Open materials include videos and case studies in agribusiness and maize and coffee pricing. The materials include 10 teaching cases, 7 multimedia DVDs, 19 community brochures, and 6 community posters. Three student master's theses were part of the AgShare work.

\section{B. Impact on Students}

The second external evaluator found that the project had a highly positive impact on the student researchers creating the multimedia materials for their action research, stating that "student-researchers benefited in several ways, but mainly in terms of their enhanced contextually relevant specialist knowledge and induction into field-based research under the guidance of academics with whom they 
worked closely. Theory and practice came together [7]."

The short duration of the pilot projects did not allow time for the AgShare materials to be widely implemented in formal courses; however, interviews with the small number of students who used the materials in courses offered during the pilot phase revealed that "students who studied the resulting OER benefited from content developed in authentic contexts and presented in interactive ways that brought the subject alive. The OER allowed them to adjust the sequencing and pacing of their own learning in line with their own needs and interests. Amongst other OER assets, students appreciated clear curriculum structure and more purposeful forms of assessment [7]."

\section{Impact on Faculty}

Interviews with faculty participating in the pilots indicated that "like their students, academics experienced the OER as an 'eye opener' that presented new and exciting possibilities for teaching. Their case study research led to new understandings of farming practices and associated value chains as well as to teaching that was now genuinely research based. In contrast with the traditional model of classroombased lecturing, the case study-based, multimedia OER resulted in a major shift in the way academics now construed their roles as teachers (rather than as lecturers) and as researchers [6,7].”

\section{Impact on Farmers}

Related to AgShare's impact on farmers, the second evaluator reported that "in direct and indirect ways, the Planning and Pilot Project has impact on several thousand farmers, primarily as a consequence of AgShare training in large farmer cooperatives. Students using questionnaires designed by two agricultural experts collected data on actual impact. The agricultural experts used the completed questionnaires to provide independent reports on project impact on farmers. Overall conclusions with respect to impact were further informed by the preliminary and draft reports of systematic studies on impact of the intervention on milk production and its quality. All data and reports indicated that AgShare had a highly positive OER impact on farmers and the broader agricultural community [7]."

\section{E. OER Re-use}

In terms of re-use of the AgShare OER, this objective occurred within the framework of existing consortia such as RUFORUM and CMAAE, where members of the consortia have shared their material with each other to facilitate re-use. At the other universities, the brief time frame of the pilots resulted in the second evaluator's conclusion that "there has been a fair amount of advocacy within OER-producers' personal networks. Nonetheless, actual 'take up' requires decision-making and university approval processes that make consideration of this form of impact premature at this stage [7]."

\section{F. Additional Impacts}

The second evaluator found that "in addition to its formal aims, AgShare had significant secondary effects. Impact extended beyond farmers to sectors of the value chain as well as contributing to the status and role of women involved in agricultural production. The third and most significant form of secondary impact was on the partner institutions themselves. By providing a conceptual model of cooperation between the university and its community, the project was seminal in the repositioning of one university to achieve its mission of teaching, research and serving the community [7]."

The AgShare pilot projects demonstrated a wide range of positive impacts. The second evaluator noted the following:

AgShare is possibly unique in having achieved a highly positive impact across a range of stakeholders from those involved in agricultural research, as well as in teaching and learning, to those engaged in agricultural production and marketing. What made this possible? Evidence from this impact assessment points to a single overarching reason: the logic and power of the AgShare model and the effectiveness of its implementation. Case study research on farms provides the basis for integrating the roles and functions of those 
who teach and learn agriculture in higher education with the productive sector and associated value chains [7].

\section{G. OER Dissemination}

The ability to disseminate information is critical to further uptake. The AgShare project team led by OER Africa and Michigan State University developed a website which followed best practices for dissemination of resources [8]. The initial design included the creation of a dedicated search engine that would scrape the website to share the resources. The programming time required to create an effective search engine promised to eat a significant portion of the budget. The team began to explore alternative options and soon located the website Coherence for Information for Agriculture Research for Development (http://www.ciard.net/). The international resources for managing web projects provided the needed information to tag resources geared toward agriculture. Each university team was provided with additional information on how to replicate the efforts on a local level [9].

\section{DISCUSSION}

The AgShare planning and pilot phase demonstrated an effect on farmers, student researchers, and faculty and students in the classroom. AgShare pilots transformed the way in which academics conceptualized their roles as teachers and researchers by validating community-based problems as research and by collaborating with students and stakeholders [10]. AgShare pilots created relevant and effective student learning in the coursework component of the master's degree, enabling students to engage with local issues versus abstract theory. AgShare pilots increased the students' capacity to conduct meaningful, high-quality, independent research, which becomes part of the public record and adds demonstrable research to the students' resumes. AgShare pilots improved farmers' practices that lead to improved quality and productivity and positioned them to begin moving away from subsistence farming. AgShare pilots produced free, openly-licensed educational resources for customization and re-use that improved the quality of teaching through relevant case studies.

\section{A. Resulting AgShare Method}

The AgShare planning and pilot phase resulted in the definition of a powerful road-tested method that provides strategies for a coherent institutional approach to teaching, research, and community development. The AgShare core strategy is a research-based approach for the co-creation and publication of purposeful agricultural knowledge within and across stakeholder groups. Multiple-media OERs provide an appropriate methodology as they are intended to be shared, modified, and made freely available through learning networks. The AgShare method as defined in the AgShare II proposal has four components:

1. Projects commence with field-based research into farmers' practices and needs. Students, working closely with their faculty supervisors, carry out this research. Research involves relevant community-wide partners within respective value chains.

2. Students, faculty, and staff participate in capacity-building workshops in research, OERs, and media production.

3. Student field research (or participatory action research) is published in three ways: as OER multimedia learning packages for incorporation into degree programs; as information for farmers used for follow-up visits and extension materials; and as research in master's thesis and undergraduate student research.

4. The OERs are published in appropriate venues leading to recognition for scholarship, teaching, research, and extension.

The research-based nature of the AgShare method, with students conducting research in the field involving multiple stakeholders, is its essential component. OERs are developed from this research by 
student and faculty teams for teaching and learning in the classroom, for extension in the field, and for scholarly research publication where appropriate.

\section{CONCLUSION}

Working in partnership with four universities around East Africa, the AgShare planning and pilot phase produced exciting results through the creation of African-based, open curricular materials that are easily localized. This work involved the incorporation of new faculty processes, active learning, and engagement by universities with community stakeholders. It also involved a graduate student research agenda that focused on serving the smallholder farm community. The process of growing open, shareable African-led, resource-based curricula will thus help to drive sustainable agriculture productivity for many years to come.

The AgShare planning and pilot phase has successfully demonstrated the value of building structured relationships between academics, students, content suppliers, and community-wide partners, such as farmers, farmers' associations, and agribusinesses to facilitate the creation and sharing of open knowledge in the form of OERs. This content is being used to build capacity and strengthen knowledge systems across the agricultural value chains targeted in the pilot.

The current phase of AgShare Phase II is focused on embedding the AgShare method into the practices of RUFORUM. The objective of Phase II is to complete the following:

Identify, produce, adapt and widely encourage the use, re-use and dissemination of relevant and contextualized African open content to build a comprehensive set of open curriculum and research resources to support new and existing Master's and course-based $\mathrm{PhD}$ level agricultural degree programs. The main focus would be on open knowledge resources that would be generated as outputs from student-centered community participatory action research activities and would aim to directly improve agricultural outcomes at different levels through targeted value chains of staple crops such as maize, coffee and legumes, as well as through livestock such as cattle and poultry [11].

Universities have a critical role to play in developing agricultural value chains around key crops and livestock. Graduates of African programs in agriculture can become the brightest future leaders in industry, government, and academia, positioned to implement impactful change that will directly and positively affect small farms and rural communities. Working together, particularly through postgraduate academic programs, faculty and students are ideally positioned to develop stronger national knowledge systems in agriculture, to build capacity right across the value chains, and to improve the quality of data used for decision making through effective research. When the intellectual property generated through this activity is released under open licensing models, it creates a sustainable platform for ongoing strengthening and development of these value chains by making knowledge publicly accessible and easy to re-version and adapt.

\section{ACKNOWLEDGEMENTS}

The authors are grateful to the many people that helped shape the AgShare concept and those who supported the work with their time and participation. The authors are especially grateful to the co-creators and partners in AgShare: Dr. John B. Kaneene of Michigan State University; Neil Butcher, Catherine Ngugi, and Dr. Alice Barlow-Zambodla of OER Africa/Saide; and Nodumo Dhlamini and Joan Apio of RUFORUM. They are especially thankful for the outstanding work of the AgShare pilot project leaders: Dr. Jemal Yousuf Hassen, Dr. John David Kabasa, Dr. Jema Haji Mohamed, Dr. Mark Ollunga Odhiambo, and Dr. Francis Wambalaba. The authors thank Ken Harley, Dr. Gashaw Kebede, Dr. Cliff Lampe, and Liz Levy and for their very significant contributions to AgShare. The authors thank the Bill \& Melinda Gates Foundation for their generous funding and Khalid Bomba for helping to shape the initiative and Brady Walkinshaw for his tireless support. 


\section{REFERENCES}

1. Geith, C., and Vignare, K. Access to Education with Online Learning and Open Educational Resources: Can They Close the Gap? Journal of Asynchronous Learning Networks (JALN) 12(1) (2008). http://www.distanceandaccesstoeducation.org/contents/JALN_v12n1_Geith.pdf.

2. Geith, C. Can OER Really Impact Higher Education and Human Development? (2008). http://www.oercommons.org/courses/christine-geith-can-oer-really-impact-higher-education-andhuman-development.

3. Adipala, E., Ochola, W., Ekaya, W., Osiru, M., and Dhlamini, N. Capacity Development for Agricultural Transformation: Making Postgraduate Level Training Relevant to Africa's Agricultural and Rural Sector Development. Paper presented to the Global Consortium on Higher Education and Research for Agriculture (GCHERA) Conference. Nairobi, Kenya. (2009).

4. Geith, C. Convening Notes. Unpublished results from Bill \& Melinda Gates Foundation convening on M.Sc. Agriculture Curriculums in Africa. Nairobi, Kenya. (2009).

5. Geith, C., and Kim, L. Lay of the Land of African Agriculture Open Educational Resources. Commissioned by the Bill \& Melinda Gates Foundation. (2008).

6. Kebede, G. Interim Report for AgShare Planning and Pilot Project. Unpublished results. (2011).

7. Harley, K. AgShare Planning and Pilot Project Impact Study. (2012). http://www.oerafrica.org/agricultureoer/AgricultureResources/ResultsPage/tabid/1784/mctl/Details/ id/39276/Default.aspx.

8. Vignare, K., Geith, C., Collins, B., and Weebadde, P. How Organizing Knowledge in Meaningful Ways Enhances Search and Supports Independent Learning. In Barriocanal, Cebeci, Okur, öztürk (Eds.), Metadata and Semantic Research 5th Internal Conference, Springer. (2011).

9. Vignare, K. Information \& Communication Technologies Provide Strategies to Improve Pervasiveness of Extension (in Africa). Modernizing Advisory and Extension Service, a USAID grant-funded project. (2013). http://www.meas-extension.org/resources/ict.

10. Geith, C., Butcher, N., Vignare, K., et al. AgShare: Building Community and Content with Multiple Partners. In Open ED 2010 Proceedings. Barcelona: UOC, OU, BYU. (2010). http://hdl.handle.net/10609/4862.

11. Barlow-Zambodla, A., Dhlamini, N., and Vignare, K. AgShare Phase II Proposal. Unpublished. (2012).

\section{ABOUT THE AUTHORS}

Christine Geith, Ph.D., is assistant provost and executive director of Michigan State University MSUglobal Knowledge and Learning Innovations. She leads the development of new entrepreneurial approaches in higher education using educational technology, online learning, and open models. Recently, she's worked with faculty to open up critical knowledge to help transform global food systems and agriculture. She was previously at Rochester Institute of Technology as co-director of the Educational Technology Center and director of Distance Learning. Christine has a Ph.D. from University of Nebraska, Lincoln, and an MBA from Rochester Institute of Technology.

Karen Vignare, Ph.D., currently serves as associate provost, the Center for Innovation in Learning at University of Maryland University College, leading the search and evaluation for next generation learning models. Karen is responsible for implementing collaborative innovations which may include prior learning, course design, analytics, adaptive learning, e-resources, open educational resources, instructional design changes, and competency based models. She was previous a director at MSUglobal at Michigan State University. MSUglobal is responsible for helping departments at Michigan State University integrate emerging technologies. She has a Ph.D. from Nova Southeastern University and an MBA from the University of Rochester's William Simon School of Business. 